\title{
IN VITRO ANTIBACTERIAL AND ANTIFUNGAL ACTIVITIES OF AQUEOUS AND ETHANOLIC LEAF EXTRACTS OF ACACIA AURICULIFORMIS
}

\author{
AMITA SHOBHA RAO ${ }^{1}$, SHOBHA KL ${ }^{1 *}$, MANJUNATH S SHETTY ${ }^{2}$, SREEDHARA R PAI K ${ }^{2}$ \\ ${ }^{1}$ Department of Microbiology, Melaka Manipal Medical College - Manipal Campus, Manipal Academy of Higher Education, Manipal, \\ Karnataka, India. ${ }^{2}$ Department of Pharmacology, Manipal College of Pharmaceutical Sciences, Manipal Academy of Higher Education, \\ Manipal, Karnataka, India.*Email: shobha.kl@manipal.edu \\ Received: 03 August 2018, Revised and Accepted: 17 September 2018
}

\section{ABSTRACT}

Objective: The present study focuses on in vitro antimicrobial properties of aqueous and ethanol leaf extract of Acacia auriculiformis tested on Grampositive cocci, Gram-negative bacilli, multidrug-resistant (MDR) Gram-negative bacilli, and fungus.

Methods: Ethanol and aqueous extracts of the leaves of A. auriculiformis were prepared. Agar well diffusion was the method for antimicrobial susceptibility. Freshly grown standard strains of Staphylococcus aureus, Enterococcus faecalis, Klebsiella pneumoniae (K. pneumoniae) , Escherchia coli (E.coli) and Pseudomonas aeruginosa, clinical strains of Streptococcus pneumoniae, Candida albicans (C. ailbicans), and MDR E. coli, and MDR Klebsiella pnuemoniae were used. Ampicillin disc $(10 \mu \mathrm{g})$ was used as control.

Results: The zone of inhibition was measured to determine the antimicrobial activity. Ethanolic extract of $A$. auriculiformis exhibited antibacterial activity against all the strains including MDR strains of $K$. pneumoniae and $E$. coli. Antifungal activity was exhibited by both aqueous and ethanol leaf extracts of $A$. auriculiformis.

Conclusion: Ethanol extract could be used against MDR K. pneumoniae and MDR E. coli. Similarly, aqueous and ethanol extract can be the drug of choice for $C$. albicans infection. Further study is necessary to evaluate the accurate compound responsible for antibacterial and antifungal activity for pharmaceutical applications.

Keywords: Acacia auriculiformis, Antimicrobial susceptibility testing, Multidrug-resistant bacteria, Klebsiella pneumoniae.

(c) 2018 The Authors. Published by Innovare Academic Sciences Pvt Ltd. This is an open access article under the CC BY license (http://creativecommons. org/licenses/by/4. 0/) DOI: http://dx.doi.org/10.22159/ajpcr.2018.v11i12.28853

\section{INTRODUCTION}

In the past two decades, the frequency of antimicrobial-resistant infections has increased in both the hospital and community. Pharmacological industries are producing many new antibiotics, and resistance to these drugs by microorganisms has increased [1,2]. Hence, there is a need for the development of drugs to prevent the infections caused by these organisms. Medicinal plants are used in the world and more so in India and this contributes significantly to primary healthcare system [3].

Synthetic drugs are not only expensive but also inadequate for the treatment of infections. It can have adulterations and side effects. In the developing countries, a major challenge seen nowadays in the global health care is the need for novel, effective, and affordable medicines to treat microbial infections $[4,5]$. For a long time, India among other countries forms the richest hub for the widest application of the medicinal plants. A number of such plants have found their applications in treating a wide range of human ailments. Drugs which are derived from natural sources have a significant role in the prevention and treatment of infections in humans. Hence, there is a need to search for new strategies to fight and control microbial infections [6].

Medicinal plants and herbs are used for the treatment of infections. Hence, their therapeutic potential, biological properties, and safety have to be considered before we take the decisions to use them. Acacia species are a rich source of polyphenolic compounds due to antioxidant property, and it is used in the prevention and therapy of various diseases including cardiovascular, neurodegenerative, and cancer $[7,8]$. Acacia auriculiformis (A. auriculiformis) also called black wattle is a common Indian medicinal plant. The present investigation focuses on in vitro antimicrobial properties of aqueous and ethanolic leaf extracts of A. auriculiformis tested on Gram-positive cocci, Gram-negative bacilli, multidrug-resistant (MDR) Gram-negative bacilli, and fungus.

\section{METHODS}

Plant collection

The fresh leaves of A. auriculiformis were collected from in and around Manipal, Karnataka, India. Its botanical identity was authenticated by a botanist.

\section{Aqueous leaf extraction}

Leaves of A. auriculiformis were washed using distilled water and then air dried at room temperature for 10 days. It was pulverized with clean mortar and pestle to fine powder and stored in a sterilized glass container at room temperature $\left(25-30^{\circ} \mathrm{C}\right)$. The aqueous extract of the leaves was prepared by crushing the leaves in mortar and pestle using sterile distilled water in the ratio of 1:1 [9].

\section{Ethanol extract preparation}

The shade dried $A$. auriculiformis roots were grinded to powder. A known amount of powdered material was added to ethanol in the ratio of 1:16. Extract was prepared using Soxhlet apparatus. The extraction was done for $48 \mathrm{~h}$ duration. The crude extracts obtained were filtered using Whatman Filter Paper No. 1. Using water bath at $40^{\circ} \mathrm{C}$, the solvent was evaporated. The dry extract was labeled and stored in the desiccator [10].

\section{Antimicrobial activity}

Agar well diffusion method was employed to study the antibacterial and antifungal susceptibility $[11,12]$. Antimicrobial susceptibility was 
determined against following strains. The American Type Culture Collection (ATCC) strains of bacteria used were Staphylococcus aureus ATCC 25923, Enterococcus faecalis ATCC 29212, Klebsiella pneumoniae ATCC 700603, Escherichia coli ATCC 25922, and Pseudomonas aeruginosa ATCC 27853 and clinical strains of Streptococcus pneumoniae (S.pneumoniae), MDR E. coli, MDR K. pneumoniae, and Candida albicans.

Sabouraud Dextrose Agar (SDA), Mueller-Hinton agar (MHA), and blood agar (for S. pneumoniae) procured from HiMedia, Mumbai, were used. The above-mentioned bacterial and fungal strains were revived by plating on nutrient agar, blood agar, and SDA, respectively. After overnight incubation at $37^{\circ} \mathrm{C}$, isolated colonies were selected. Identification of the organisms was done by standard procedure. Isolated bacterial colonies were then transferred to sterile MuellerHinton broth, and C. albicans was transferred to Sabouraud Dextrose Broth and incubated overnight. 0.5 McFarland's turbidity standard was used to adjust the concentration of the growth of microorganisms to $10^{5} \mathrm{CFU} / \mathrm{ml}$. Ampicillin disc $(10 \mu \mathrm{g})$, oxacillin disc $(1 \mu \mathrm{g})$, gentamicin disc $(10 \mu \mathrm{g})$, and ketoconazole disc $(10 \mu \mathrm{g})$ obtained from HiMedia, Mumbai, were used as controls [13].

\section{Determination of antibacterial activity}

Blood agar and MHA measuring $20 \mathrm{ml}$ each were poured into Petri dishes. The bacterial culture was spread over the surface of the MHA plate and blood agar. Wells of $6 \mathrm{~mm}$ diameter were punched into the agar and filled with $100 \mu \mathrm{l}$ solution of test compound. The inoculated plates were incubated in an incubator for $18 \mathrm{~h}$ at $37^{\circ} \mathrm{C}$. Tests were done in triplicates, and the average of the three was considered for the study.

\section{Determination of antifungal activity}

Nearly $20 \mathrm{ml}$ of SDA was poured into each Petri dish. Culture of the C. albicans was spread over the surface of the SDA plate. Wells were punched into the agar plate measuring $6 \mathrm{~mm}$ in diameter and filled with $100 \mu \mathrm{l}$ solution of test compound. The plates were then kept in the incubator for $18 \mathrm{~h}$ at $37^{\circ} \mathrm{C}$. Tests were done in triplicates, and the average of the three was considered for the study.

\section{RESULTS}

Diameter of the zone of inhibition was measured for the antimicrobial activity. Ethanol extract exhibited antibacterial activity against all the strains, and MDR K. pneumoniae and MDR E. coli strain had zone of inhibition measuring $13 \mathrm{~mm}$ and $14 \mathrm{~mm}$, respectively, whereas they were resistant to ampicillin. Staphylococcus aureus ATCC 25923 showed a zone of inhibition of $18 \mathrm{~mm}$ and no zone of inhibition with aqueous extract. Antifungal activity was exhibited by aqueous and ethanolic extracts with zone of inhibitions measuring $9 \mathrm{~mm}$ and $17 \mathrm{~mm}$ diameter. Both the aqueous and ethanol extracts of the leaves were found to have antifungal activity $(\mathrm{p}<0.05)$ [Table 1].

\section{DISCUSSION}

In the present scenario, antimicrobial resistance is very common. Bacteria and fungi continue to develop drug resistance by employing various mechanisms to survive in the lethal environment created by antimicrobials [14]. It is now the requirement of developing the alternative drug line to treat infectious diseases caused by MDR organisms such as Staphylococcus aureus, K. pneumoniae, and E. coli.

Attention has been given more toward the extracts and biologically active compounds isolated from plants. Plant-derived drugs have been reported to be safe and without side effects; hence, much attention has been given to these natural products as new therapeutic agents [15]. Medicinal plants play a key role in the basic health needs in developing countries. These plants offer new source of antibacterial, antifungal, and antiviral agents with significant activity against infective microorganisms [16-18].

Saba Riaz et al. showed that the pods of Acacia are commonly used in the traditional therapy of various diseases [19]. Our study supports the valuable use of $A$. auriculiformis against organisms.
Table 1: Zone of inhibition of ethanol and aqueous leaf extract of Acacia auriculiformis against various microorganisms

\begin{tabular}{lll}
\hline Name of the organism & \multicolumn{2}{l}{$\begin{array}{l}\text { Zone of } \\
\text { inhibition (mm) }\end{array}$} \\
\cline { 2 - 3 } & $\begin{array}{l}\text { Ethanol } \\
\text { extract }\end{array}$ & $\begin{array}{l}\text { Aqueous } \\
\text { extract }\end{array}$ \\
\hline Staphylococcus aureus ATCC 25923 & 18 & - \\
Enterococcus faecalis ATCC 29212 & 13 & - \\
Klebsiella pneumoniae ATCC 700603 & 7 & - \\
Escherichia coli ATCC 25922 & 10 & - \\
Pseudomonas aeruginosa ATCC 27853 & 15 & - \\
Streptococcus pneumoniae & 10 & - \\
MDR Escherichia coli & 14 & - \\
MDR Klebsiella pneumoniae & 13 & - \\
Candida albicans & 17 & 9 \\
\hline
\end{tabular}

MDR: Multidrug resistant, ATCC: American Type Culture

Collection, (-): Indicates no zone of inhibition

The present study observation was that the alcoholic extracts showed significant antibacterial activity against clinically isolated multidrugresistant microorganisms when compared to aqueous extracts and this was supported by other investigators [20,21]. The effectiveness of the extracts mainly depends on the type of solvent used and the ability of the solvent to extract more active ingredients from the plant materials [22].

Antifungal activity against $C$. albicans was exhibited by both aqueous and ethanol leaf extracts of $A$. auriculiformis in this study. This might be due to the fact that the antifungal bioactive components such as alkaloids, lectins, terpenes, and saponins can be easily extracted by water. Ethanol extract of the leaves showed more inhibitory activity than that of the control drug used, and this was supported by other investigators $[23,24]$.

\section{CONCLUSION}

The result of the present study suggests for further investigation, as ethanol leaf extract of $A$. auriculiformis showed antibacterial effects, especially on MDR K. pneumoniae and MDR E. coli which can be used against these strains as they are a threat to the community. Aqueous or ethanol extract can be the choice for infections caused by $C$. albicans. Further, purification of the bioactive principle will result in more significant activity. Our results also support the idea that herbal medicines with medicinal value have a promising future in regard to the discovery of new substances.

\section{AUTHORS' CONTRIBUTIONS}

All the authors have substantially contributed in the research and publication of this study.

\section{CONFLICTS OF INTEREST}

Authors have no conflicts of interest to declare.

\section{REFERENCES}

1. Gislene NG, Juliana L, Paulo FC, Giuliana SL. Antibacterial activity of plant extracts and phytochemicals on antibiotic resistant bacteria. Braz J Microbiol 2000;31:247-56.

2. Cohen ML. Epidemiology of drug resistance: Implications for a postantimicrobial era. Science 1992;257:1050-5.

3. Bhalodia NR, Shukla VJ. Antibacterial and antifungal activities from leaf extracts of Cassia fistula 1: An ethnomedicinal plant. J Adv Pharm Technol Res 2011;2:104-19.

4. Ventola CL. The antibiotic resistance crisis Part 1: Causes and threats. P T 2015;40:277-83.

5. Sieradzki K, Wu SW, Tomasz A. Inactivation of the methicillin resistance gene mec A in vancomycin-resistant Staphylococcus aureus. Micro Drug Resist 1999;5:253-7. 
6. Herath HM, Chamikara MD, Dissanayake DR, Dissanayake MD, Ishan $\mathrm{M}$, Rajapakse $\mathrm{S}$, et al. A comparative assessment of the antibacterial activity in fruit juice of Sri Lankan sweet orange cultivars vis-a-vis sour orange. J Agric Sci 2016;11:13-23.

7. Sarah SS, Khairulmazmi A, Natrah FM, Siti II, Kamaruzaman S. Antibacterial activity of Acacia Spp. Leaves extracts against Xanthomonas oryzaepv. Oryzae and screening for active phytochemical contents. IOSR J Agricu Vet Sci 2017;10:49-60.

8. Malini M, Abirami G, Hemalatha V, Annadurai G. Antimicrobial activity of ethanolic and aqueous extracts of medicinal plants against waste water pathogens. Int J Res Pure Appl Microbiol 2013;3:40-2.

9. Rai KS, Murthy KD, Karanth KS, Rao MS. Clitoria ternatea (Linn) root extract treatment during growth spurt period enhances learning and memory in rats. Indian J Physiol Pharm 2001;45:305-13.

10. Shakya VK, Saxena S, Shakya A. Effect of ethanolic extract of Allium sativum bulbs on streptozotocin induced diabetic rats. J Chem Pharm Res 2010;2:171-5.

11. Girish HV, Satish S. Antibacterial activity of important medicinal plants on human pathogenic bacteria-a comparative analysis. World Appl Sci J 2008;5:267-71.

12. Rao AS, Rashmi KS, Nayanatara AK, Kismat A, Dharnappa P, Sheila RP. Effect of antibacterial and antifungal activities of Sesamum indicum World J Pharm Res 2013;2:1676-80.

13. Rao AS, Nayanatara AK, Kaup SR, Sharma A, Kumar BA, Bhavesh D, et al. Potential antibacterial and antifungal activity of aqueous extract of Cynodon dactylon. Int J Pharm Sci Res 2011;2:2889-93.

14. Sekyere JO, Asante J. Emerging mechanisms of antimicrobial resistance in bacteria and fungi: Advances in the era of genomics. Future Microbiol 2018;13:241-62.

15. Rai M, Acharya D, Wadegaonkar P. Plant derived-antimycotics; Potential of Asteraceous plants. In: Plant-Derived Antimycotics. Current Trends and Future Prospects. New York: Hartworth Press;
2003. p. 165-95.

16. Maher O, Mohamad S, Mohammad AA, Enas AZ, Hanee AD, Maisa AQ, et al. Antimicrobial activity of crude extracts of some plant leaves. Res J Microbiol 2012;7:59-67.

17. Munoz MD, Acero N, Llinares F, Pozuelo JM, Galan de A, Mera VJ. Biological activity of extracts from Catalpa bignonioides Walt. (Bignoniaceae). J Ethonopharm 2003;87:163-7.

18. Sujata P, Biswajit D, Aditya JB, Bikash G. Preliminary phytochemical screening and in vitro anti-microbial activity of ethanolic extracts of fruits of Annona reticulata against standard pathogenic strains. Int J Curr Pharm Res 2018;10:59-63.

19. Saba R, Faisal M, Shahida H, Naveed AK. Antibacterial and cytotoxic activities of Acacia nilotica Lam (Mimosaceae) methanol extracts against extended spectrum beta-lactamase producing Escherichia coli and Klebsiella species. Trop J Pharm Res 2011;10:785-91.

20. Venkatadri B, Arunagirinathan N, Kumar MR, Latha R, Dhanasezhian A, Agastian P. In vitro antibacterial activity of aqueous and ethanol extracts of Aristolochia indica and Toddalia asiatica against multidrug-resistant bacteria. Indian J Pharm Sci 2015;77:788-91.

21. Dabur R, Gupta A, Mandal TK, Singh DD, Bajpai V, Gurav AM, et al. Antibacterial activity of some Indian medicinal plants. Afr J Tradit Complement Altern Med 2007;4:313-8.

22. Saranya VT, Gowrie SU. Phytochemical analysis and in vitro studies on antibacterial, antioxidant and anti-inflammatory activities using Casuarina equisetifolia bark extracts. Int J Pharm Pharm Sci 2018;10:118-25

23. Cowan M. Plant products as antimicrobial agents. Clin Microbiol Rev 1999; $12: 564-82$.

24. Darshan D, Hitesh J, Tarun K, Manthan K, Karen PR, Payal P. Evaluation of antibacterial and antifungal activity of fenugreek (Trigonellafoenumgraecum) extracts. Int J Pharm Pharm Sci 2016;8:212-7. 